\title{
Serão eles o que a gente foi? Karitiana, Puruborá e dois povos indígenas isolados em Rondônia
}

\author{
Are they what we were? \\ Karitiana, Purubora and two isolated \\ Indigenous people in Rondônia
}

Felipe Vander Velden ${ }^{1}$

\begin{abstract}
Resumo
Analisando as relações entre dois povos indígenas que vivem em intenso contato há tempos com a sociedade dita nacional ou envolvente - os Karitiana e os Puruborá - e dois grupos em isolamento voluntário em suas respectivas regiões (norte e centro-oeste do estado de Rondônia), este artigo defende que as populações indígenas vizinhas de povos isolados devem, necessariamente, ser levadas em conta quando da formulação de políticas para os povos não contatados, uma vez que a presença destes tem substanciais consequências para, dentre outras, as políticas territoriais daqueles.

Palavras-chave: Rondônia, Karitiana, Puruborá, índios isolados, território.
\end{abstract}

\begin{abstract}
Through the analysis of the relationships between two indigenous peoples that have been living integrated in mainstream Brazilian society for decades — the Karitiana and the Puruborá - and two uncontacted groups in their territories (northern and centralwestern Rondonia, respectively), this article contends that indigenous peoples living in the neighbourhoods of uncontacted groups must be accounted when public policies are designed for these, because the presence of these isolated peoples has meaningful consequences for territorial politics of contacted peoples.
\end{abstract}

Keywords: Rondônia, Karitiana, Puruborá, uncontacted peoples, territory.

\section{Introdução}

Não deixa de ser espantoso saber que no estado de Rondônia, tão duramente devastado pelas frentes de expansão extrativistas e agropecuárias que varreram a Amazônia ocidental principalmente a partir dos anos de 1970 (e que continuam com seus efeitos devastadores ainda nos dias de hoje),

1 Departamento de Ciências Sociais/Universidade Federal de São Carlos (UFSCar) felipevelden@yahoo.com.br 
ainda existem vários grupos indígenas que rejeitam o contato com agentes do estado e da sociedade dita nacional ou envolvente, e mesmo com seus vizinhos imediatos, sejam estes indígenas ou não. As notícias, como em geral acontece, são incertas, mas fala-se em cinco grupos cuja existência é confirmada e monitorada pela Coordenação Geral de Índios Isolados e Recém Contatados (CGIIRC) da FUNAI, além de outros cinco grupos cuja existência resta por ser confirmada e são, assim, definidas como "em estudo" (Altini \& Bavaresco 2011; Vaz 2013a: 18-29). Outras mais podem, claro, existir, sem serem conhecidas pelas instituições oficiais e por organizações não governamentais, ainda que possa se afirmar com poucas dúvidas que todas elas enfrentam a difícil situação de serem acossadas pela brutal ocupação das últimas áreas verdes do estado (Santos 1996).

A título de ilustração, pelo tempo em que estive em Rondônia no ano de 2011 notícias diversas sobre a localização de novos grupos sem contato pipocavam com certa frequência no trabalho de monitoramento efetuado pela então atuante Frente de Proteção Etnoambiental do Madeira, lotada em escritório próprio na sede administrativa da Fundação Nacional do Índio na capital, Porto Velho. Novas informações, via de regra fragmentárias, frequentemente enigmáticas, chegavam vez por outra dando conta de avistamentos de "índios bravos" por caçadores e garimpeiros ou da localização, por parte de mateiros ou pescadores, de vestígios de artefatos e de acampamentos de grupos isolados muito recentemente abandonados, em certos casos às pressas. Em 2009, por exemplo, uma expedição que percorreu a Estação Ecológica Serra dos Três Irmãos/Mujica Nava, em Porto Velho, encontrou evidências da presença de índios isolados que estariam numa faixa que variava entre 10 e 30 quilômetros do canteiro da Usina Hidrelétrica de Jirau, no rio Madeira² ${ }^{2}$. Em 19 de maio de 2010 um relatório da ONG Survival International denunciou que quatro grupos não contatados corriam riscos em função da proximidade de seus territórios das instalações das enormes hidrelétricas de Jirau e de Santo Antônio ${ }^{3}$. Nas palavras do indigenista Rogério Vargas Motta, então coordenador, em 2011, da Frente de Proteção Etnoambiental do Madeira, ao menos "dois desse grupos estão seriamente ameaçados pela construção das hidrelétricas de Santo Antonio e Jirau no rio Madeira" (GTA - Regional Rondônia 2008: 44; ver também Vaz 2013b: 31-33). Há de se fazer referência, ainda, ao caso do assim chamado Índio do Buraco (Reel 2011), cuja triste trajetória de solidão ecoa a história de Ishi, the last of the Yahis (Kroeber 1964).

Meu objetivo neste texto, contudo, não é avaliar a notável presença de povos em isolamento voluntário em Rondônia e no sudoeste da Amazônia

\footnotetext{
${ }^{2} \mathrm{http} / / / \mathrm{www} . b a n k t r a c k . o r g /$ show/article/expedicao_confirma_presenca_de_indios_isolados perto_de_hid reletrica_em_ro (acesso em 27/09/2016).

${ }^{3}$ https://uc.socioambiental.org/pt-br/arp/826 (acesso em 27/12/2016).
} 
brasileira, tão devastados pela expansão desenfreada da assim chamada sociedade nacional, mas discutir a imagem deles construídas e manipuladas por duas populações indígenas na região, os Karitiana e os Puruborá, que mantêm contatos esporádicos com pelo menos dois grupos não contatados. Contato, aqui, deve-se deixar claro, não remete apenas à experiência efetivas de encontros pessoais, na floresta ou nas aldeias, entre indivíduos ou grupos. Trata-se, antes, de fazer referência mais ampla à presença de certos grupos isolados na história recente e no que poderíamos chamar de imaginário cotidiano desses dois povos indígenas já com algum tempo de convívio com a sociedade envolvente e com instituições estatais. Com efeito, os isolados frequentam a reflexão contemporânea tanto dos Karitiana quanto dos Puruborá (mais dos primeiros do que dos segundos, é verdade) de maneiras singulares, mesmo que as notícias a respeito deles sejam fragmentárias e costumeiramente carregadas de incertezas. Não obstante, os discursos que registrei nessas duas comunidades sobre os índios isolados ou bravos configuram-se como elementos importantes no modo como ambas refletem sobre alguns de seus problemas atuais, especialmente àqueles ligados aos respectivos territórios. Defendo, aqui, como já defendi em outro lugar (Vander Velden 2015), que as políticas públicas desenhadas para as populações indígenas sem contato, não contatadas, isoladas, arredias, livres, autônomas, em isolamento voluntário (Parellada \& Alcântara 2007) ou - porque denominações importam (Shepard Jr. 2016; Opas 2016) - em relativo isolamento (High 2013: 195, 201) ou sem contato com braços dos estados nacionais, ou seja, "não cadastrados" (Bonilla \& Capiberibe 2015) ${ }^{4}$ devem, necessariamente, levar em conta as reflexões acerca destes coletivos por povos indígenas vizinhos. Minha reflexão neste texto alinha-se a outros trabalhos que se destacam a importância de se dar voz às opiniões, desejos e projetos dos atores locais - sobretudo indígenas (Howard 2002; High 2013; Opas 2016) - que, afinal, vivenciam a questão bem de perto, e que podem ter papel crucial no encaminhamento das relações interétnicas nas regiões, para o bem (estabelecimento e direcionamento do contato) ou para o mal (emergência de conflitos mais ou menos graves).

As reflexões tanto dos Karitiana como dos Puruborá a respeito de seus elusivos vizinhos falam de uma espécie de temporalidade preservada. Para ambos os grupos, uma das possibilidades mais interessantes é tratar os isolados como parentes que os deixaram há tempos atrás. Esses parentes, contudo, seguiram como que parados no tempo, vivendo nos recônditos da floresta sem o

\footnotetext{
${ }^{4}$ Já que a ideia de "contato" é tão problemática de acordo com vários autores, assim como a de "isolamento" (porque, na maioria dos casos, o que há parece ser tão somente um isolamento seletivo ou parcial), talvez fosse melhor falar em uma recusa do convívio. Mantém-se contato, ou contatos, mas furta-se ao convívio, àquilo que a (hoje praticamente em desuso) classificação dos graus de integração dos povos indígenas com a sociedade nacional chamava de contato intermitente (Ribeiro 1996).
} 
contato com os brancos e todas as enormes transformações por ele acarretadas. Eles seriam, hoje, o que os Karitiana e os Puruborá foram no passado, antes de aceitarem a convivência definitiva com a sociedade envolvente. Tal elaboração sugere que narrativas da não coetaneidade (Fabian 2002) talvez não sejam restritas ao pensamento ocidental, que com muita frequência pensa seus outros como habitando tempos distintos, e sempre pretéritos (o "primitivo", o "arcaico", o "tradicional"), de sua própria modernidade ou contemporaneidade. Os Puruborá e os Karitiana também refletem sobre seus vizinhos isolados como seres do passado. Não obstante, um possível (e às vezes desejado) encontro com eles deve trazer consequências importantes para os dois povos, de acordo com seus plamejamentos para uma futura convivência, como veremos na sequência.

\section{Os Karitiana e os Baixinhos}

Falantes de uma língua Tupi-Arikém, os Karitiana são, atualmente, cerca de 320 pessoas, que habitam cinco aldeias no norte do estado de Rondônia, nos municípios de Porto Velho e Candeias do Jamari. A Terra Indígena Karitiana constitui um quadrilátero quase perfeito de aproximadamente 89 mil hectares de área, tendo sua cobertura florestal ainda bastante preservada, especialmente na sua porção meridional. Nestas matas, no canto sudeste da terra indígena, encontram-se, de acordo com os Karitiana, os índios bravos, os Baixinhos, assim chamados, evidentemente, por sua reduzida estatura ${ }^{5}$. Este grupo em isolamento voluntário é designado nas fontes oficiais como "Referência 45", sendo conhecidos também como "isolados da Floresta Nacional (FLONA) do Bom Futuro", "isolados do Bom Futuro" (Vaz 2013a: 28) ou ainda "isolados do rio Candeias" (Santos 1996: 551). Trata-se de um dos grupos isolados menos conhecidos em Rondônia, cujo estatuto oscila entre o "confirmado" (majoritariamente por fontes locais ou regionais) e o "em estudo" (estatuto oficial), e sobre o qual as informações são esparsas e desencontradas. Assim, Marcelo dos Santos (1996: 551) observa, em meados da década de 1990:

As informações a respeito desse grupo ainda são muito inconsistentes, e foram repassadas por posseiros ao membro da não-governamental Aparai, Manoel Valdez, há mais de dois anos (...).

A situação de desconhecimento permanece, hoje, praticamente idêntica. Mesmo entre os Karitiana as notícias são dúbias. Nos meus primeiros períodos

\footnotetext{
${ }^{5}$ O qualificativo "baixinho" usado para fazer referência a povos não contatados ocorre em outras partes do Brasil (como é o caso, por exemplo, de pelo menos dois grupos em Mato Grosso, conforme Comegna 2008), e se insere numa lista de exodenominações em geral derrogatórias que se concentram em características físicas dessas pessoas das (sobre as ou com as) quais não se pode saber muito mais coisa: "índios brancos", "coroados", "barbados", "cabeças secas", entre outros.
} 
de campo em suas aldeias, entre 2003 e 2009, ouvi muitas histórias sobre a presença recente dos Baixinhos nas imediações da aldeia Kyõwã, a maior e mais antiga das atuais aldeias deste grupo indígena. Nos últimos anos, contudo, sua presença parece ter se dissipado, e o grupo talvez tenha efetivamente desaparecido, ou se deslocado para áreas mais distantes dos assentamentos permanentes dos Karitiana. Assim, Cizino e Meireles, na aldeia do rio Candeias, contaram em 2015 que

Não tem mais índio bravo aqui, brancos fazendeiro já matou tudo. Fazendeiro falou para mim que achou índio bravo bem perto daqui [da aldeia do rio Candeias], duas mulheres, um menino novo e um homem, e atirou por cima deles, eles correram. Mas fazendeiro atirou para matar

Os Karitiana especulam bastante a respeito da identidade desses que denominam os Baixinhos. Uma das possibilidades mais recorrentes sobre a possível identidade étnica deste grupo isolado seria a de se tratar de uma parcialidade ainda livre dos Uru-Eu-Uau-Uau, o grupo Tupi-Kagwahiwa estabelecido ao sul do território Karitiana. Uma significativa coleção de histórias narra ataques dos Uru-Eu-Uau-Uau contra os Karitiana, que reportam episódios de um conflito quase permanente nos últimos cem anos, que só se conclui - ou, pelo menos, deixa de lado seus aspectos mais sangrentos - com a pacificação dos primeros em meados da década de 1980 (Leonel Jr. 1995). Os Karitiana temem os Uru-Eu-Uau-Uau, que consideram guerreiros ferozes e sanguinários: Yryposopipok, seu nome na língua Karitiana, significa "gente grande e forte que não se deixa atingir por flechas porque é muito rápida"6. Alguns homens Karitiana participaram, como empregados da FUNAI, do processo de pacificação dos Uru-Eu-Uau-Uau: logo que puderam estabelecer os primeiros diálogos amistosos com estes antigos inimigos, ouviram da boca dos próprios guerreiros Kagwahiwa que, antes do contato definitivo, estes chegavam muitas vezes bem perto das aldeias Karitiana (Leonel Jr. 1995). Há, deste modo, uma tensão sempre presente nas relações entre esses dois povos indígenas (cf. França 2012: 49), aparentemente inimigos históricos. Os Karitiana, portanto, temem os Uru-Eu-Uau-Uau, e postulam que os Baixinhos bem podem ser uma de suas parcialidades ainda não contatadas. Sabem, outrossim, que na Terra Indígena Uru-Eu-Uau-Uau, logo ao sul da Terra Indígena Karitiana, a FUNAI confirma de fato a existência de pelo menos três grupos em isolamento voluntário (Simonian 1991).

\footnotetext{
${ }^{6}$ Os Karitiana apreciam as belas flechas confeccionadas pelos Uru-Eu-Uau-Uau, com suas enormes pontas barbadas de taquara e emplumação de variadas cores. É comum que tais flechas sejam exibidas pelos guerreiros Karitiana junto aos arcos e flechas de fabricação própria - estas muito menos vistosas - nas manifestações políticas na capital rondoniense ou em outras localidades.
} 
Entretanto, uma das mais intrigantes possibilidades de identificação dos Baixinhos aponta para a percepção, por parte dos Karitiana, de que o grupo isolado pode ser aparentado, tendo resultado de uma fissão deste povo ocorrida muito tempo atrás. Com efeito, os Karitiana especulam que os índios isolados da FLONA do Bom Futuro podem ser os descendentes de Yjko, um homem que, na companhia de sua mulher e sua filha, deixou a aldeia Karitiana e desapareceu na floresta - desta forma, os isolados seriam, então, parentes. Junto de sua pequena família, Yjko abandonou seu povo devido à problemas com sua esposa (violada, segundo consta, por outros homens da aldeia); nunca mais foram vistos, nem tampouco tiveram mais notícias deles. Yjko era mesmo chamado, de acordo com as narrativas contemporâneas, "o isolado" - de certo modo sugerindo avant la lettre seu estatuto futuro - , porque mesmo antes de desaparecer para sempre já vivia afastado dos demais Karitiana, em uma casinha apartada das grandes casas redondas multifamiliares do passado, tal como reconta Antônio José Karitiana:

Depois, no dia seguinte foi um monte de gente na casa do isolado [Yjko] para amansar ele, mas quando chegaram não tinha mais ninguém. Yjko foi embora, não deixou nem rastro, largou para trás tudo o que tinha na casa dele. Aí as pessoas ficaram tristes.

Estes eventos possivelmente se desenrolaram em um momento de enormes alterações na trajetória histórica dos Karitiana, muito provavelmente no final do século XIX, momento em que a penetração das frentes de expansão da sociedade brasileira se intensifica nesta porção do noroeste do Brasil. O contato nem sempre pacífico com os novos colonizadores da região acaba por conduzir à fragmentação do povo Tupi-Arikém então estabelecido entre os vales dos rios Candeias, Jamari e Jaci-Paraná, como destaca outro narrador, Antônio Paulo, grande contador de histórias:

Aí os Karitiana foram para todo lado, e se perderam. Nunca mais conseguiu encontrar um monte de parente [...] os Karitiana estão espalhados, não se encontram mais.

Assim, os Baixinhos podem se revelar, eventualmente, parentes, os "filhos perdidos de Yjko", como se diz (cf. Vander Velden 2015). Eles seriam um grupo Karitiana que, tendo permanecido na floresta sem contato com outros coletivos humanos indígenas ou não indígenas, teriam conservado a "braveza" que caracterizava os próprios Karitiana antes do convívio com os brancos. O próprio afastamento deste grupo - de certo modo já previsto em sua história (em seu nome) antes de deixarem o convívio com seus semelhantes - contribui para sua estranheza e os perigos que cercam o contato com eles, lembrando que, na Amazônia, a solidão e o isolamento são perigosos indícios de comportamentos 
anti-sociais (High 2013: 211). Sua baixa estatura, entretanto, indica a direção contrária, uma vez que os Karitiana hoje se pensam como muito menores do que seus antepassados, efeito deletério das vicissitudes do contato: da alimentação estranha e antinatural, dos medicamentos, e da intensa fumaça produzida por veículos, máquinas e queimadas promovidas pela colonização de Rondônia. Nesse sentido, os Baixinhos tampouco poderiam ser Uru-Eu-Uau-Uau, uma vez que estes, aos olhos dos Karitiana, são ambiguamente celebrados pela compleição alta e forte de seus corpos: os Uru-Eu-Uau-Uau fornecem, então, e algo paradoxalmente - dada a inimizade entre os dois grupos - a imagem contemporânea daquilo que foram os Karitiana no passado não tão distante (High 2013: 208).

De todo modo, a língua é caracterizada pelos Karitiana como o critério decisivo para um eventual futuro das relações entre os dois grupos: se a língua dos Baixinhos for inteligível — isto é, se se revelar o mesmo idioma dos Karitiana - eles serão acolhidos e a convivência será firmada; caso contrário, caso a comunicação se mostre impossível, vão, como dizem, "meter bala". Neste caso, a ausência da capacidade linguística apropriada tornaria esses índios isolados como animais de presa, "caça grande", ou "comida", como se diz usualmente, uma vez que com os animais caçados não se dialoga, a única relação possível sendo a predação cinegética e o consumo de sua carne. Nas palavras do pajé Cizino, "os Karitiana não aprenderam as línguas dos outros índios, não podem falar com eles e entender eles, por isso, eles são comida".

Ainda assim, a possibilidade de que os Baixinhos sejam os descendentes de Yjko aguça a imaginação dos Karitiana, e sugere a necessidade e a urgência de sua proteção. De fato, uma grande área de floresta ainda cobre a região compreendida entres os flancos leste e sudeste da Terra Indígena Karitiana e as margens do rio Candeias, e é aí, numa zona também pouco frequentada pelos Karitiana, que provavelmente se ocultam os isolados do Bom Futuro, escapando da lenta mas persistente penetração de madeireiros, fazendeiros e caçadores clandestinos. Em julho de 2011, uma expedição organizada pela FUNAI e composta por dois jovens Karitiana e dois servidores da Frente de Proteção Etnoambiental do Rio Mandeira percorreu parte desta área. A expedição esteve por vinte dias na mata e, embora não tenha avistado os isolados - fator determinante, como se sabe, para a afirmação de sua existência como povo autônomo e para a conversão do estatuto da referência de "em estudo" para "confirmada"-, trouxe uma coleção de fotografias e outros materiais que a FUNAI local tomou como provas que confirmam que a "Referência 45" ainda radica ali ${ }^{7}$. As fotografias mostram as evidências mais comuns atribuídas a grupos sem contato nas terras baixas sulamericanas: galhos e ramos quebrados pelos caminhos, perfurações em árvores para a provável coleta de mel, cortes em troncos para extração de fibras vegetais,

${ }^{7}$ As conclusões da expedição podem ser consultadas em Mota (2011). 
vestígios de fogueiras, entre outros. Todos estes indícios foram considerados imediatamente como produtos indígenas, por mais que os cortes e perfurações nas árvores parecessem ter sido feitos com ferramentas de metal - forma, ao fim e ao cabo, de inserção desses isolados na história (e de contestação da própria ideia de "isolamento"), uma vez que se postula que podem ter acumulado machados e terçados de metal roubados de acampamentos não indígenas na região, ou mesmo tê-los recebido diretamente dãos mãos de não índios com quem podem ter estabelecido relações esporádicas em algum momento. Com estas ferramentas de metal, os Baixinhos aproximam-se algo mais dos Karitiana em sua trajetória temporal da "braveza" ao contato. Com isso, talvez deixem de ser bichos, comida, para se tornarem potenciais parentes.

\section{Os Puruborá e seus homens antigos}

Os Puruborá, falantes de uma língua Tupi-Puruborá - hoje em estudo e recuperação pelo povo indígena, que se expressa basicamente no Português regional (Galúcio 2005) - vivem em uma única aldeia situada entre os municípios de Seringueiras e de São Francisco do Guaporé, no centro-oeste de Rondônia. A aldeia Aperoí abriga, hoje em dia, 12 famílias Puruborá, cerca de 40 pessoas, mas muitas mais famílias deste povo (fala-se entre 200 e 1000 indivíduos) vivem espalhadas pela região e por outras cidades do estado e do país (Menezes 2016: 37-38). Neste momento, os Puruborá lutam pela identificação e delimitação da Terra Indígena Puruborá que, formalmente, ainda não existe: a aldeia Aperoí constitui um agregado de casas dispersas - à guisa de um bairro rural - habitadas por uma parentela e alguns agregados, situado em terras que foram obtidas por compra pelo falecido casal fundador do território, cuja mulher, Dona Emília, é reconhecida por todos como uma espécie de matriarca (Menezes 2016). Sendo assim, é fundamental avaliar a relação dos Puruborá com um grupo isolado vizinho tendo-se em vista o processo de reconhecimento dos direitos territoriais deste povo, cujas raízes se encontram na trajetória histórica do mesmo território.

Os Puruborá têm, como muitos outros povos vizinhos, uma história de contato bastante violenta. Localizados por Rondon no início do século XX (em 1909) e concentrados no posto indígena Três de Maio (do SPI) nas cabeceiras do rio Manuel Correia (um tributário do rio São Miguel) alguns anos depois, onde foram postos a trabalhar na extração de borracha e da castanha na companhia de seringueiros oriundos, sobretudo, da região Nordeste do país, já em meados do século os Puruborá foram considerados mestiçados com a população regional, perdendo, assim, a assistência oficial. Entre as práticas comuns à situação dos Puruborá no seringal então dirigido por José Félix do Nascimento, empregado do Serviço de Proteção aos Índios, estava aquela de ceder as mulheres indígenas em casamento como prêmio aos seringueiros não 
índios com maior produtividade. Com isso, ao longo do tempo, os homens Puruborá vão paulatinamente desaparecendo da história deste grupo: conforme mostrou o trabalho de Tarsila Menezes (2016), os Puruborá são uma sociedade fortemente matrifocal, em que as mulheres não apenas figuram praticamente sozinhas como pontos chave nas genealogias como, atualmente, são maioria, ocupam posições políticas importantes e estão à frente na luta pela recuperação de suas terras tradicionalmente ocupadas.

Começando no início do novo milênio, a mobilização política dos Puruborá para reaver suas terras entrou em rota de colisão com a proteção especial concedida pela FUNAI à Terra Indígena Uru-Eu-Uau-Uau, localizada um pouco ao norte da região ocupada pelos Puruborá e zona de perambulação de pelo menos três grupos indígenas putativamente Tupi-Kagwahiwa em isolamento voluntário (Leonel Jr. 1995; Simonian 1991). Ocorre que parte dos Puruborá habitava a região conhecida como Cigana, às margens do alto rio Manuel Correia, quando da demarcação efetiva da Terra Indígena Uru-Eu-UauUau nos anos de 1990; naquela ocasião, técnicos da FUNAI não reconheceram ali um grupo indígena, mas tão somente camponeses, que foram obrigados a se retirar. Desde então, desceram o Manuel Correia até as proximidades com sua confluência com o igarapé Caio Espíndola, zona onde fundaram a aldeia Aperoí e que ocupam até o presente. Não obstante, logo que a reivindicação Puruborá por suas terras tradicionais se fez ouvida, nos princípios dos anos 2000 (Monserrat 2005; Galúcio 2005), a FUNAI — pressionada pelos Uru-EuUau-Uau (e Amondawa) habitantes da terra indígena homônima - convocou as lideranças Puruborá para uma reunião em que eles foram proibidos de, na sua luta pela terra, reclamar porções do território que hoje compõem a Terra Indígena Uru-Eu-Uau-Uau. Os Puruborá contam mesmo que foram ameaçados por guerreiros Uru-Eu e Amondawa, para que de forma alguma ultrapassassem os limites da T.I. mesmo nas andanças necessárias ao reconhecimento oficial e ao processo de identificação e delimitação de uma futura terra indígena Puruborá. Parte da preocupação da FUNAI com as reivindicações Purborá, logicamente, radica na presença dos isolados na região: um dos grupos reconhecidamente transita pelo extremo sul da Terra Indígena Uru-Eu-Uau-Uau, bem próximo às fazendas que, nos limites daquela T.I., são consideradas parte do território tradicionalmente ocupado pelos Puruborá.

Em 2014, durante minha pesquisa de campo em Aperoí, os Puruborá receberam uma notícia que atiçou sua curiosidade a respeito dos índios isolados da chamada "Referência 49", também conhecidos como "Isolados do Bananeira", cuja existência como grupo Tupi-Kagwahiwa (por vezes denominado Jururei, cf. Silva 2010: 241) é confirmada (Vaz 2013a: 26) e vem sendo monitorada por funcionários da FUNAI que mantêm na área um posto de vigilância (Bananeira). A narrativa aqui reproduzida foi feita por um colega do campus de Ji-Paraná da Universidade Federal de Rondônia, que a ouviu dos estudantes indígenas da instituição: 
Durante uma expedição da FUNAI pelo sul da Terra Indígena UruEu-Uau-Uau, do rio Cautário para o posto Bananeira, dois caçadores Amondawa que estavam na floresta com a equipe encontraram uma bando de porcos do mato e começaram a correr atrás deles para cercálos e matá-los com flechas. No meio da correria, quando se peceberam, se deram de frente com um índios bravo, Ywyrapararikwara, índio sem camisa, que também estava atrás dos mesmos porcos. Eles estavam correndo lado a lado, mas só perceberam isso depois de algum tempo. A atenção estava no porco, que era o objetivo dos caçadores. Não viram os outros. Quando viram, estavam frente a frente com o índio pelado, com suas flechas. O homem Amondawa falou com o índios isolado, para ele não correr que não iam fazer nada com ele. Eram dois índios isolados, que faralarm entre si. Mas os Amondawa não entenderam, não entenderam o que falaram os outros índios. Eles conversaram, mas não se entenderam. Nem uma palavra. É outra língua

Se os Amondawa não compreenderam a língua deste grupo sem contato que habita a porção meridional da Terra Indígena Uru-Eu-Uau-Uau, pode-se supor que eles não sejam falantes da língua Tupi-Kagwahiwa comum, com pequenas variações dialetais, tanto aos Uru-Eu-Uau-Uau quanto aos Amondawa (Sampaio 1998). Teríamos, assim, um grupo não-Kagwahiwa nas regiões mais ao sul da Terra Indígena Uru-Eu-Uau-Uau (ainda que as referências sustentem sua identificação como Kagwahiwa), o que não seria improvável, uma vez que esta zona que divide as águas dos afluentes do Madeira (para o norte) e do Guaporé (para o sul) marca também os limites meridionais dos grupos Kawahiwa, onde estes tradicionalmente encontravam os povos de língua Tupari, Mondé, Ramarama e Puruborá, além de povos de língua Txapakura (Nimuendajú 1981).

É assim que os Puruborá passaram a especular se os isolados que percorrem o sul da Terra Indígena Uru-Eu-Uau-Uau não poderiam ser esses homens, seus parentes, fugidos do seringal de José Félix por inconformidade com as violências sofridas e com o fato de que suas mulheres passaram a ser moeda de troca na economia da borracha. Sem esposas, e submetidos às sevícias do patrão não índio - ainda que nomeado formalmente pelo SPI — , os homens Puruborá teriam optado por permanecer na floresta, afastados do mundo dos brancos. Segundo relatos dos anciãos, José Félix obrigava os índios a cortarem seringa e coletarem castanha em troca de mercadorias. Ele teria conseguido atrair apenas poucos homens Puruborá para o seringal, e há especulações que mesmo esses homens teriam morrido por conta de epidemias. Já os homens Puruborá, que não foram atraídos para o seringal, revoltados, teriam fugido, e permanecido isolados nas matas da região, e, supostamente, seriam os antepassados do grupo indígena sem contato que perambula pelo sul da Terra Indígena Uru-Eu-UauUau (Menezes 2016: 113).

Portanto, nesse grupo não contatado do Bananeira, os Puruborá de hoje 
buscam reencontrar seu vigoroso passado - o do "povo das onças" ou "que se transforma em onça" (Galúcio 2005) - em um presente repleto de ausências feito, justamente, pela busca das práticas e saberes perdidos ao longo da história de sofrimento e opressão: a língua, o xamanismo, os mitos, tudo o que, trazido do passado - das memórias dos mais idosos e dos raros documentos etnográficos remanescentes - permitirá afirmar com mais veemência a etnicidade dos Puruborá, recorrentemente negada desde há mais de meio século (Galúcio, Puruborá \& Aporete Filho 2013; Montanha, Barboza \& Oliveira 2014). Neste cenário atual de reconstrução da identidade, a existência destes parentes antigos, evadidos para as matas e conservados em liberdade, seria uma aquisição de imenso valor estratégico.

Note-se, antes de concluirmos, que as especulações tanto dos Karitiana quanto dos Puruborá a respeito de seus vizinhos em isolamento voluntário revolvem, ambas, em torno dos grupos não contatados que perambulam pela imensa área de floresta preservada pela Terra Indígena Uru-Eu-Uau-Uau e pelo Parque Nacional dos Pacaás Novos e seus arredores. Tal zona constitui precisamente a área de penetração dos grupos de língua Kagwahiwa pelo centro do atual estado de Rondônia em seu deslocamento originado na bacia do médio Madeira entre os séculos XVIII e XIX (Menéndez 1981/82; Peggion 2011a e 2011b), o que acaba por desenhar nesta zona não apenas a fronteira entre os conjuntos etno-linguísticos Kagwahiwa e Txapakura (Leonel Jr. 1995), mas também por separar os povos falantes de línguas de diversas famílias do tronco Tupi: os Mondé, Tupari, Ramarama e Puruborá ao sul, e os Karitiana ao norte.

Mais do que uma questão restrita à etnologia regional, contudo, é necessário destacar que os dois casos aqui tratados sustentam o argumento, defendido por vários autores (Kirsch 1997; High 2013; Bessire 2014), de que o "isolamento" não é uma condição natural ou primordial, mas fruto da história e da economia política de exploração e violência que assolam a Amazônia e outras partes da América do Sul há pelo menos cinco séculos. Mais do que uma condição inata — traduzida pela ideia de "povos perdidos" (lost peoples) — a recusa do contato ou do convívio fala de processos sociais de escala regional, continental ou global cujos desdobramentos nos rincões mais distantes produzem e expressam diferenças por vezes tão inconciliáveis e agressões tão avassaladoras que a opção mais sábia parece mesmo ser o afastamento e o isolamento voluntários, mesmo que relativo. Não se trata, assim, de gente isolada, mas de gente que se isolou.

\section{Considerações finais}

A ideia de que grupos indígenas livres, não contatados ou em isolamento voluntário de hoje são imagens do passado de povos indígenas que há muito convivem com os brancos não é restrita aos Karitiana e Puruborá: reflexão 
análoga existe também, e é bastante bem explorada, por exemplo, entre os Awá-Guajá no oeste do Maranhão, para quem os pequenos coletivos isolados designados como Awá Mihua (os inimigos, os outros) vivem ainda no chamado "tempo da floresta", tal como viveram todos os Awá-Guajá que, hoje, habitam aldeias sedentárias nas proximidades dos postos da FUNAI (Garcia 2010). Esses Awá-Guajá ditos "arredios" ou "bravos", deste modo, constituem-se como uma imagem perfeita do passado autônomo de todos os Awá-Guajá no interior fresco e sombreado das matas, ainda que este seja um tempo eivado de ambiguidades: o "tempo da floresta" é percebido como um misto de prazer e medo, de uma vida ideal e de condições miseráveis de existência. Tal se reflete na maneira como os Mihua são pensados pelos demais Awá-Guajá "aldeados", por assim dizer: simultaneamente admirados por sua liberdade e autenticidade e desprezados por suas incompetências diante das novidades do presente e por seus hábitos anacrônicos e, no limite, inumanos. Eles são o passado Awá-Guajá, é fato, mas um passado para o qual um desejado retorno é, no mínimo, discutível. Não obstante, duas temporalidades também parecem cindir o povo Awá-Guajá, assim como acontece nas reflexões dos Karitiana e dos Puruborá vis-à-vis seus respectivos vizinhos não engolfados pela sociedade nacional envolvente (Garcia 2010). Casey High (2013) descreve uma situação semelhante entre os Waorani na Amazônia equatoriana, que também refletem sobre os grupos não contatados na sua região (os Taromenani) como gente de tempos antigos (like the ancient ones; High 2013: 199), fierce warriors reminiscent of their ancestors and kismen who became disconnected from other Waorani in past times (High 2013: 197).

As narrativas aqui analisadas a respeito do que pensam duas sociedades indígenas em contato permanente com a sociedade mais ampla acerca de seus vizinhos arredios falam desta ausência de coetaneidade entre frações distintas do que supostamente seriam um mesmo povo. Imagens de primitivismo e de ahistoricidade, certamente, mas imagens fortemente ambíguas: o presente tem vantagens, mas as perdas acumuladas pela história fazem pensar nas possibilidades abertas pela descoberta do passado de certa forma congelado nesses "índios bravos" que parecem ser então, simultaneamente, os mesmos e os outros. Se estes grupos sem contato vivenciam a história e o tempo a seus modos - modos sobre os quais, evidentemente, nada sabemos - aos olhos de seus vizinhos eles parecem representar o potencial de reaver um passado cuja materialidade tem importantes consequências para as políticas indígenas e indigenistas no Brasil contemporâneo. Isso é mais evidente para o caso dos Puruborá, que ainda lutam por reconhecimento; mas é também crucial para os Karitiana no processo que atualmente movem pela proteção de seu território e pela reconquista de antigas terras tradicionalmente ocupadas que foram excluídas da demarcação formal de seu território nos anos de 1970. Tal constatação sugere que, mais do que pensar na "destruição cultural" dos isolados trazida pela efetivação do convívio, é possível refletir também sobre 
formas de "revitalização cultural" de povos vizinhos que nutrem interesse por estes grupos em isolamento justamente porque eles supostamente portam ainda aqueles saberes e práticas que os novos tempos de convívio fizeram desaparecer.

Que o isolado seja, ao final, o mesmo pode atender à expectativas de reivindicação de terras e também de resgate de um tempo e de um saber perdidos, e mesmo a possibilidade de resgatar corpos como eram antigamente, já que os corpos indígenas de hoje são muito diferentes, menores e menos potentes, devido às violências do processo de contato e ao tratamento sórdido dado ao mundo pelos não índios. Conhecer os povos indígenas livres ou em isolamento voluntário a partir da ótica de seus vizinhos, assim, pode ter múltiplas implicações para as políticas públicas voltadas aos povos sem contato ou em contato inicial. Inserir os Karitiana e os Puruborá nas discussões e nas ações relativas às "referências 45 e 49 " será fundamental para a efetiva proteção dos Baixinhos na Floresta Nacional do Bom Futuro e dos Ywyrapararikwara na Terra Indígena Uru-Eu-Uau-Uau. Neste último caso, mais do que afastar os Puruborá das atividades de monitoramento e proteção aos isolados do Bananeira, deve-se trazê-los ao debate, mesmo porque planeja-se, no futuro, que suas terras constituam uma espécie de zona tampão entre a região ocupada pelo grupo sem contato e os principais aglomerados urbanos do centro do estado de Rondônia.

Os dois grupos parecem planejar estratégias de abordagem semelhantes no caso destes isolados se revelarem mesmo "parentes": o contato amigável e, paulatinamente, a incorporação e o convívio, ainda que esses desejos, claro, não estejam isentos de múltiplos problemas, como mostram vários casos de contato entre povos indígenas contatados e grupos em isolamento relativo ou nos estágios iniciais de contato (Cabodevilla, Smith \& Rivas 2004; Arisi 2007; Gow 2011; High 2013; Bessire 2014). No caso Puruborá, isso terá enorme importância para a luta pelos direitos étnicos e territoriais deste povo. No caso dos Karitiana, igualmente, para a garantia efetiva de seu território histórico ignorado pela demarcação da Terra Indígena homônima. Os efeitos da eventual constatação do não parentesco (quer seja, da diferença e da incomunicabilidade), por outro lado, pedem precauções - tal como avisam os Karitiana - e nos alertam para o necessário cuidado para que os contextos locais não descambem para um cenário de miséria, violência e anomia extremas, como acontece ainda hoje nas relações entre Ayoreo contatados e não contatados no norte do Paraguai (Bessire 2014) e entre os Waorani e os Taromenani do oriente equatoriano (High 2013). Deve-se ter atenção, deste modo, com o potencial para que as próprias ações dos povos indígenas contatados para com seus vizinhos não contatados não reproduzam as relações de dominação colonial que ainda hoje caracterizam os encontros entre índios e não índios nas terras baixas da América do Sul (Milanez \& Shepard Jr. 2016: 131).

A garantia dos territórios tradicionalmente ocupados por dois povos há muito contatados - os Puruborá e os Karitiana — pode, assim, redundar na 
proteção de coletivos em situação de isolamento, sendo estes reconhecidos como parentes ou não. Identificar e demarcar a Terra Indígena Puruborá, devolver aos Karitiana seus territórios que, no vale do rio Candeias, foram excluídos da demarcação oficial: assim se poderá consolidar, com maior chance de sucesso, a proteção a dois grupos indígenas sem contato, possibilitando aos Puruborá e aos Karitiana ao menos o sonho de um encontro no mínimo instigante com o que pode se revelar algo de seu passado ou o reencontro com saudosos parentes que partiram há muito tempo.

\section{Referências}

Altini, Emília \& Bavaresco, Volmir. 2011. "Povos indígenas isolados ameaçados pelos grandes projetos em Rondônia", en Gustavo Loebens \& Lino Neves (orgs.): Povos indígenas isolados na Amazônia: a luta pela sobrevivência. Manaus: EDUA/CIMI: 87-98.

Arisi, Bárbara. 2007. Matis e Korubos: contato e índios isolados no vale do Javari, Amazônia. Dissertação de mestrado, Florianópolis, UFSC.

Bessire, Lucas. 2014. Behold the black cayman: a chronicle of Ayoreo life. Chicago: University of Chicago Press.

Bessire, Lucas. 2014. Behold the black cayman: a chronicle of Ayoreo life. Chicago: University of Chicago Press.

Bonilla, Oiara \& Capiberibe, Artionka. 2015. "Isolados ou cadastrados: os índios na era desenvolvimentista". Revista $D R$, número 1 (disponível em http://revistadr.com. br/posts/isolados-ou-cadastrados-os-indios-na-era-desenvolvimentista, acesso em 16/01/2017).

Cabodevilla, Miguel; Smith, Randy \& Rivas, Alex. 2004. Tiempos de guerra: Waorani contra Taromenane. Quito: Abya-Yala.

Comegna, Maria Angela. 2008. "Políticas de proteção aos povos indígenas isolados no Brasil e na Bolívia". Diez años de cambios en el Mundo, en la Geografía y en las Ciencias Sociales, 1999-2008. Actas del X Coloquio Internacional de Geocrítica, Universidad de Barcelona, 26-30 de mayo de 2008. (disponível em http://www.ub.es/geocrit/-xcol/89.htm, acesso em 15/01/2017).

Fabian, Johannes. 2002. Time and the other: how anthropology makes its object. New York: Columbia University Press.

França, Luciana Barroso Costa. 2012. Caminhos cruzados: parentesco, diferença e movimiento entre os Kagwahiva. Tese de doutorado, Rio de Janeiro: MN-UFRJ.

Galúcio, Ana Vilacy. 2005. "Puruborá: notas etnográficas e linguísticas recentes". Boletim do Museu Paraense Emílio Goeldi - Série Ciências Humanas, vol. 1, nº 2: 159-192.

Galúcio, Ana Vilacy; Puruborá, José Evangelista \& Aporete Filho, Paulo. 2013. Vocabulário ilustrado: animais na Língua Puruborá. Belém: MPEG.

Garcia, Uirá. 2010. Karawara: a caça e o mundo dos Awá-Guajá. São Paulo: USP, tese 
de doutorado.

Gow, Peter. 2011. “'Me deixa em paz!' Um relato etnográfico preliminar sobre o isolamento voluntário dos Mashco". Revista de Antropologia, 54(1): 11-46.

GTA - Regional Rondônia. 2008. O fim da floresta: a devastação das unidades de conservação e Terras Indígenas no estado de Rondônia. Porto Velho: Grupo de Trabalho Amazônico — GTA Rondônia.

High, Casey. 2013. "Lost and found: contesting isolation and cultivating contact in Amazonian Ecuador". HAU: Journal of Ethnographic Theory, 3(3): 195-221.

Howrd, Catherine. 2002. Wrought identities: Waiwai expeditions in search of the unseen 'tribes' of Northern Amazonia. PhD dissertation, University of Chicago.

Kirsch, Stuart. 1997. "Lost tribes: indigenous people and the social imaginary". Anthropology Quarterly, 70 (2): 58-67.

Kroeber, Theodora. 1964. Ishi in two worlds: a biography of the last wild indian in North America. Berkeley: University of California Press.

Leonel Jr., Mauro. 1995. Etnodicéia Uruéu-au-au. San Pablo: Edusp/IAMÁ

Menezes, Tarsila. 2016. O passado, o presente e o futuro nas plantas Puruborá (Rondônia). São Carlos, PPGAS-UFSCar, dissertação de mestrado.

Menéndez, Miguel. 1981/82. "Uma contribuição para a etno-história da área TapajósMadeira”. Revista do Museu Paulista, 28 (nova série): 289-388.

Milanez, Felipe \& Shepard Jr., Glenn. 2016. "The few remaining: genocide survivors and the Brazilian state". Tipití: Journal of the Society for the Anthropology of Lowland South America, 14 (1): 131-134.

Monserrat, Ruth Maria. 2005. "Notícia sobre a língua Puruborá". In: A. Dall'Igna Rodrigues \& A. S. A. Câmara Cabral (orgs.), Novos estudos sobre línguas indígenas. Brasília: Editora UnB.

Montanha, Gisele; Barboza, José Joaci \& Oliveira, Anatália. 2014. "Puruborá: mitos de um povo indígena ressurgido da Amazônia”. Tellus, 27: 151-174.

Mota, Rogério Vargas. 2011. Relatório de Expedição na Terra Indígena Karitiana e na Floresta Nacional do Bom Futuro, Referência $N^{o}$ 45. Porto Velho: FPEM/FUNAI, não publicado.

Nimuendajú, Curt. 1981. Mapa etnohistórico de Curt Nimuendajú. Rio de Janeiro: IBGE/Fundação Nacional Pró-Memória

Opas, Minna. 2016. "On the significance of representations concerning indigenous people in voluntary isolation". Tipiti: Journal of the Society for the Anthropology of Lowland South America, 14 (1): 141-144

Parellada, Alejandro \& Alcântara, Maria Lourdes B. de. 2007. Povos indígenas em isolamento voluntário ou contato inicial na Amazônia e no Gran Chaco. São Paulo: Núcleo Interdisciplinar do Imaginário e Memória — USP/IWGIA.

Peggion, Edmundo. 2011a. Relações em perpétuo desequilíbrio. A organização dualista dos povos Kagwahiva da Amazônia. São Paulo: ISA/Annablume/Fapesp. 
2011b. "Conflitos e alianças indígenas no sul do Estado do Amazonas. O caso dos Tenharim do rio Marmelos (Tupi-Kagwahiva)".In: Edilene Coffaci de Lima \& Lorena Córdoba (eds.), Os outros dos outros: relações de alteridade na etnologia sul-americana. Curitiba: UFPR, pp. 71-82.

Reel, Monte. 2011. O último da tribo: a epopeia para salvar um índio isolado na Amazônia. San Pablo: Companhia das Letras.

Ribeiro, Darcy. 1996. Os índios e a civilização. São Paulo: Companhia das Letras.

Sampaio, Wany Bernardete. 1998. Estudo comparativo sincrônico entre o Parintintin (Tenharim) e o Uru-eu-uau-uau (Amondava): contribuições para uma revisão na classificação das linguas tupi-kawahib. Campinas: Unicamp, dissertação de mestrado.

Santos, Marcelo dos. 1996. "Índios acossados em Rondônia”. In: C. A. Ricardo (org.), Povos Indígenas no Brasil 1991-1995. São Paulo: Instituto Socioambiental, pp. $550-553$

Shepard Jr., Glenn. 2016. "Ceci n'est pas un contacte: the fetishization of isolated indigenous people along the Peru-Brazil border". Tipiti: Journal of the Society for the Anthropology of Lowland South America, 14 (1): 135-137.

Silva, Adnilson. 2010. Territorialidades e identidade do coletivo Kawahib da Terra Indigena Uu-Eu-Wau-Wau em Rondônia: 'orevaki are'(reencontro) dos 'marcadores territoriais. Curitiba: UFPR, tese de doutorado

Simonian, Lígia. 1991. "Os Uru-Eu-Wau-Wau e os Amundáwa no início dos anos noventa”. In: Carlos Alberto Ricardo (ed.), Aconteceu especial: Povos Indígenas no Brasil 1987/88/89/90. São Paulo: CEDI, pp. 423-425.

Vander Velden, Felipe. 2015. "Los niños perdidos de Yjko: historia y alteridad en las relaciones de los karitianas con los 'bajitos' de la FLONA de Bom Futuro (Rondonia, Brasil)”. In: Cecilia Martínez \& Diego Villar (eds.), En el corazón de América del Sur (vol. 2). Santa Cruz de la Sierra: Biblioteca del Museo de Historia, pp. 213-228.

Vaz, Antenor. 2013a. "Brazil. State policy: from custody to the policy of rights - a solved issue?". In: IWGIA/IPES (org.), Indigenous peoples in voluntary isolation and initial contact. Copenhagen/Pamplona Iruñea: IWGIA/IPES: 12-55.

. 2013b. Povos indígenas isolados e de recente contato no Brasil: políticas, direitos e problemáticas. Brasília: Edição do Autor.

Recebido em agosto de 2016

Aceito em setembro de 2016 